six deaths were classified as lymphosarcoma where only one would be expected. ${ }^{1}$ A further study was made of these six deaths: in one patient the diagnosis was schwannoma but in five it was lymphosarcoma proved by biopsy. All five were Jewish and four of these were immigrants from Eastern Europe.

If the excess deaths among the pathologists reported by $\mathrm{Dr}$ Harrington and $\mathrm{Mr}$ Shannon were due to lymphosarcoma it is certainly more than coincidental that in both these studies death from lymphosarcoma should be much greater than expected. Two possibilities occur to me. If a higher proportion than expected of the pathologists were also Jewish there may be a genetic factor involved. The other possibility is that doctors may be more exposed to some risk factor, perhaps a virus infection. There may be a combination of both genetic and en vironmental factors. We need more information from the death certificates of the six pathologists in this group. It does not appear likely that better diagnosis in doctors could account for such a big difference between the actual and expected number of deaths in this group because if better diagnosis alone was responsible one would expect the same difference in other conditions, such as the leukaemias.

GEOFFREY DEAN

Medicosocial Research Board,

Dublin

1 Dean, G, South African Medical fournal, 1969, 43, 495 .

Folic acid deficiency during intensive therapy

SIR,-We were interested to read the work $^{1}$ and comments (8 November, p 344) of Dr C A J Wardrop and his colleagues.

While we agree that there is a close parallel between their report and ours (18 October, $p$ 145), there are two important differences. Our patients were both fit before admission and the first was a young man in full health before his accident, whereas the patients studied by Dr Wardrop and his colleagues may already have been on the borderline of folic acid deficiency. It is true that both our patients had been fed intravenously and one had received an estimated $300 \mathrm{~g}$ of ethanol over nine days, but the other received only Intralipid and Vamin which do not contain ethanol.

We have also seen another case of some interes in this context. The patient was a woman of 58 years who had an operation for an oesophageal stricture in December 1974. She required intravenous feeding postoperatively, but no ethanol was given at this time. Two months later further surgery was required and by this time she may well have become folate-depleted. Intravenous feeding included ethanol on this occasion, the total dosage being $180 \mathrm{~g}$ over seven days. She was slightly thrombocytopenic before ethanol was begun bu within a week of beginning this treatment he platelet count dropped to $15 \times 10^{9} / 1\left(15000 / \mathrm{mm}^{3}\right)$ and she died soon afterwards. Her bone marrow three days before death was megaloblastic.

The effect of ethanol on the bone marrow is well documented." Alcoholics are of ten folic-acid-deficient because of a dietary lack, but there is also evidence that folic acid metabolism is inhibited by alcohol, perhaps via inhibition of tetrahydrofolate formylase. Vacuolation of erythroid precursors and sideroblastic change have also been de- scribed. We have reviewed our slides and have found no evidence of vacuole formation. Siderotic granules are increased in number but there are no ring sideroblasts and the degree of megaloblastosis is quite sufficient to account for the increased amounts of iron.

We have reviewed our records from February to October 1975 inclusive. Most of the $19175 \mathrm{~g}$ of ethanol used for intravenous feeding during this period was contained in Aminoplex 5. The total number of patients admitted to the intensive therapy unit was 230 , of whom about $26 \%$ received intravenous feeding and $15 \%$ were fed for more than five days. We have therefore used significant amounts of ethanol without difficulty in many patients. It is of course possible that many factors, including other constituents of the intravenous diet, might be responsible for the changes observed. Theoretically glycine and methionine, both of which are present in Vamin, might precipitate megaloblastosis."

Finally, this syndrome may have been described as long ago as 1943.' Certainly the cases described by Saary et al ${ }^{5}$ recently are very like ours and no mention of intravenous feeding is made. They review the literature and discuss the mechanism of the megaloblastosis without reaching a firm conclusion. From our experience we conclude that this acute syndrome is multifactoral in origin but we agree that ethanol and/or amino-acid infusions may contribute to the problem.

R M IBBOTSON

B T Colvin

M P Colvin

Departments of Haematology and Anaesthetics,
The London Hospital Medical College, London E1 1. Wardrop, C A J, et al, Lancet, 1975, 2, 640,
Straus, D J, Seminars in Haematology, 1973, 10 , 183

Waxman, S, et al, fournal of the American Medical Association, 1970, 214, 101

Limarzi, L R, and Levinson, S A, Archives of Pathology, 1943, 36. 127 Saath, M, et al, fournal of Clinical Pathology,
1975, 28, 324.

\section{Smoke-polluted food}

SIR,-You are to be congratulated on your leading article (15 November, p 370), being almost alone among the press to support the Prince of Wales in his insistence on postponing the loyal toast, and smoking, until after the sweet.

May he be now encouraged to go further and delay the toast until diners have had a chance at least to savour the port with a palate unsullied by tobacco fumes.

Hove, Sussex

REX BINNING

\section{Redistribution of resources}

SIR,-The Secretary of State for Health and Social Services proposes to redistribute resources for health care, and few would argue against the basic objective of helping the deprived regions and areas.

The distribution of financial resources within the Health Service shows two major anomalies: it is uneven as between differen parts of the country and, equally, as between the various specialties. The Secretary of State's proposals seem to take into accoun the first anomaly but not the second, the danger being that certain specialties (for example, psychiatry, mental handicap, and psychogeriatrics) which have been financially underprivilegd for years may now suffer an even worse fate under this proposed financial redistribution than will other specialties which have done comparatively better in the past.

It has taken years of persistent struggle to achieve a tolerable (if not adequate or satisfactory) standard of care for patients suffering from mental handicap and psyohiatric and psychogeriatric disorders. It is therefore a pity that the little progress so far made in these fields should stand threatened yet again. One wonders if the decisionmakers will ensure that these underprivileged specialties do not suffer in the intended redistribution.

The above-mentioned specialties, by the very nature of the problems the patients face, demand that they be treated near to their home environment and away from large institutions. This concept of care near to the patient's environment has taken years to evolve and is being pursued with vigour and effectiveness, and much to the consumers' satisfaction and benefit. It would be a very retrograde step indeed if-for financial or administrative reasons-regions, areas, and districts were to divert resources from local community services and facilities into large institutions and away from the patients' immediate environment. Such an exercise, although expedient to finance officers and tidy administrators, is likely to have very undesirable long-term consequences both for the patients and the specialties concerned.

At present these dangers are only anticipated, but they could easily become real unless the people involved are prepared actively to dispel them. St Christopher's Day Hospital,
Horsham, Sussex

N H RATHOD

\section{Junior hospital staff contract}

SIR,-We, the undersigned junior radiologists in the Greater Glasgow area, feel that any contract based on extra duty allowances or units of medical time would be unprofessional and could affect adversely recruitment into radiology.

We would not, therefore, be prepared to take industrial action to support implementation of the proposed new contract or to support retention of the existing contract and would recommend that negotiations begin again towards a contract based wholly on an adequate basic salary without extra payments.

JOHN F CALDER and 20 others

Glasgow

SIR,-The continuing furore over the junior hospital doctors' contract prompts me to write to express views which, I believe, are held by many doctors but which have not as yet received due acknowledgment from some of our negotiators, the media, or the public at large.

The first point that needs to be repeatedly emphasised is that we as hospital doctors are primarily concerned with maintaining standards in the National Health Service. This inevitably means not only an increase in 